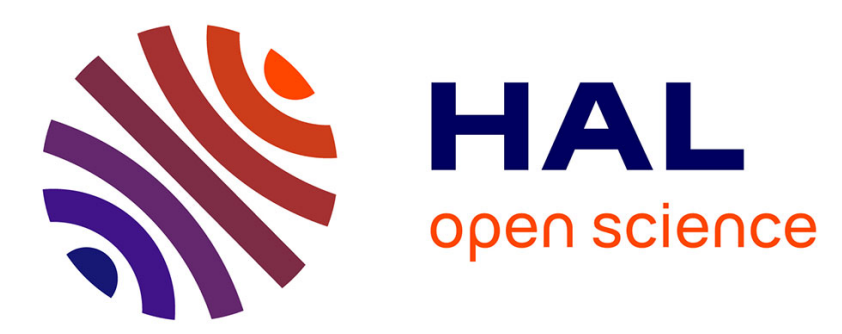

\title{
Effect of chromium on void swelling in ion irradiated high purity $\mathrm{Fe}-\mathrm{Cr}$ alloys
}

\author{
A. Bhattacharya, E. Meslin, J. Henry, A. Barbu, S. Poissonnet, B. Décamps
}

\section{To cite this version:}

A. Bhattacharya, E. Meslin, J. Henry, A. Barbu, S. Poissonnet, et al.. Effect of chromium on void swelling in ion irradiated high purity Fe-Cr alloys. Acta Materialia, 2016, 108, pp.241-251. 10.1016/j.actamat.2016.02.027 . cea-02421731

\section{HAL Id: cea-02421731 https://hal-cea.archives-ouvertes.fr/cea-02421731}

Submitted on 6 Mar 2020

HAL is a multi-disciplinary open access archive for the deposit and dissemination of scientific research documents, whether they are published or not. The documents may come from teaching and research institutions in France or abroad, or from public or private research centers.
L'archive ouverte pluridisciplinaire HAL, est destinée au dépôt et à la diffusion de documents scientifiques de niveau recherche, publiés ou non, émanant des établissements d'enseignement et de recherche français ou étrangers, des laboratoires publics ou privés. 


\title{
Contribution of helium and injected self-ions to the reduction of void swelling in ion-irradiated $\alpha$-iron: a transmission electron microscopy study
}

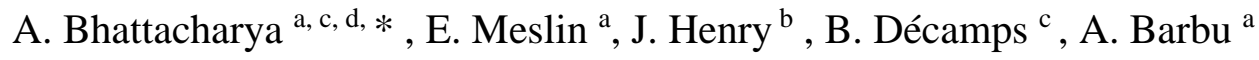
Affiliations :

${ }^{a}$ DEN-Service de Recherches de Métallurgie Physique, CEA, Université Paris-Saclay, F91191, Gif-sur-Yvette, France

${ }^{b}$ DEN-Service de Recherches Métallurgiques Appliquées, Laboratoire d'Analyse Microstructurale des Matériaux, CEA, Université Paris-Saclay, F-91191, Gif-sur-Yvette, France

${ }^{c}$ Centre de Sciences Nucléaires et de Sciences de la Matiére (CSNSM/IN $\left.{ }_{2} P_{3} / C N R S\right)$, University of Paris Sud, Batiment 108, F-91405 Orsay Campus, France

d. Materials Science and Technology Division, Oak Ridge National Laboratory, 1 Bethel Valley Road, Oak Ridge, TN, 37980, USA.

\begin{abstract}
Effect of helium on void swelling was studied in high-purity iron, irradiated using energetic self-ions to $157 \mathrm{dpa}$ at $773 \mathrm{~K}$, with and without helium co-implantation upto 17 appm He/dpa. Microstructure characterization by transmission electron microscopy revealed compelling evidence of dramatic swelling reduction by the addition of helium, achieved primarily by reduction of size of the cavities. A comprehensive understanding of helium effects is developed and discussed using the sink strength ratios of dislocations and cavities. Results also show unexpected drastic suppression of void swelling adjacent to the damage peak, which we attribute to the so called injected interstitial effect.
\end{abstract}

Keywords: Iron; ion irradiation; transmission electron microscopy (TEM); cavity nucleation; helium.

\section{Introduction}


In the future fusion reactors, the steel structural materials will be exposed to high neutron dose of up to 150 - 200 displacements per atom (dpa) at elevated temperatures up to 973 K, [1 - 3]. Apart from irradiation damage, helium gas will be produced in the steels by (n, $\alpha$ ) transmutation reaction, in amounts depending on the neutron spectrum, fluence, and alloy composition [2, 4, 5]. Specifically for the fusion reactors, helium generation rate for steels by $14 \mathrm{MeV}$ neutrons is expected to be $~ 10-12 \mathrm{appm} \mathrm{He/dpa} \mathrm{[4,} \mathrm{5].} \mathrm{The} \mathrm{interaction} \mathrm{of} \mathrm{such}$ large levels of helium with the radiation induced defects will largely complicate the radiation damage scenario. It is, hence, of paramount importance that helium induced microstructure modifications, its interaction with radiation induced defects and the ensuing consequences on material properties be evaluated with rigour. The study of radiation effects on simple high purity bcc Fe is of particular interest because it is the base element for the structural steels envisaged for use in the next generation of nuclear reactors. Moreover, in such model materials, the fundamentals of the radiation effects are relatively simpler to understand owing to the absence of alloying elements and impurities, known to interact strongly with radiation induced defects [6-8].

Many previous studies have shown that helium drastically degrades mechanical properties of metals and ceramics $[9,10]$, predominantly owing to preferential nucleation of helium stabilized cavities on the grain boundaries at high temperatures [Ref]. This behaviour induces grain boundary weakening, developing a tendency for inter-granular cracking [4]. However, the most well-known and relatively less understood phenomenon is the influence of helium on the nucleation and growth of cavities which causes void swelling [4, 9, 11]. It is largely accepted in the international community that helium causes void swelling by facilitating cavity formation. Ab-initio calculations on the interaction of helium atoms with vacancies in bcc Fe have shown that the primary role of helium is to stabilize vacancy clusters $[12,13]$. Thisconclusion is derived from the observed strong binding energy of vacancies to 
helium atoms and to helium-vacancy (He-V) clusters. This theoretical result is experimentally validated. As for example, transmission electron microscopy (TEM)-based experimental studies of Brimbal et al. [11] showed an order of magnitude increase in cavity number density in high purity bcc Fe which was irradiated simultaneously by $2 \mathrm{MeV} \mathrm{Fe}^{2+}$ self-ions and 2 $\mathrm{MeV}$ energy degraded $\mathrm{He}^{+}$ions to $100 \mathrm{dpa}$, co-implanted with 26 appm He/dpa at $773 \mathrm{~K}$, as compared to the situation when no helium was implanted. Positron lifetime measurements in pure Fe have also shown that helium favours the formation of cavities as compared to hydrogen [14]. However, contrary to popular belief, void swelling was seen to decrease upon helium addition by Brimbal et al [11]. It was noted to be $0.40 \%$ when no helium was present, which then reduced to $0.31 \%$ and $0.2 \%$ by co-implantation of 250 appm and 2500 appm helium respectively. The average cavity size was seen to decrease from $24 \mathrm{~nm}$ to $7.2 \mathrm{~nm}$ for the highest helium implantation dose. Similar observations in pure Fe were noted by Kuramoto et al. [15] after single beam and dual beam irradiations using $4 \mathrm{MeV}$ Ni ions and a continuous energy varying helium ion beam at 723 and $773 \mathrm{~K}$ to $50 \mathrm{dpa}$, 10 appm He/dpa. Apart from these studies, to the best of our knowledge, a detailed analysis of void swelling behaviour induced by helium during ion irradiations on high purity bcc Fe is not available in the literature. However, a large void swelling data set after ion and neutron irradiations is present in the literature for steels and other metallic materials where in majority of the cases enhanced void swelling occurred due to helium [16 - 22] and in many other cases reduced swelling was observed [11, 15, 23-25]. This symbolises that helium may have a dual role on swelling. Nevertheless, an increase of swelling due to helium is well explained because helium addition would enhance cavities, but not the contrary. To well-understand the role of helium on void swelling, we have performed dedicated ion irradiation experiments on a very high purity bcc Fe to high dose ( $>100 \mathrm{dpa}$ ) at $773 \mathrm{~K}$ with and without simultaneous helium implantation. 
The sample was produced at the Ecole des Mines, Saint Etienne, and received as a cylindrical rod of $1.1 \mathrm{~cm}$ diameter, in recrystallized state, after a cold reduction of 70\%. It was then annealed at $973 \mathrm{~K}$ for 1 hour under pure argon flow, to reach larger grain sizes and low dislocation density. The resulting mean grain size was $183 \mu \mathrm{m}$ and the dislocation density was of the order of $10^{12} \mathrm{~m}^{-2}$. The nominal impurity concentration of the material is given in Table 1. Circular discs of $1 \mathrm{~mm}$ thickness were cut from the as-received rods using a Struers cutting saw. They were then mechanically polished to mirror finish by silicon carbide/diamond abrasives to $100 \mu \mathrm{m}$ thickness, using a Struers grinding / polishing machine. Then, discs of 3 mm diameter were punched out and jet-electropolished in a bath containing $5 \%$ percloric acid in ethanol at $-40{ }^{\circ} \mathrm{C}$ for a few seconds in a Tenupol-5 thinning device to obtain mirror polished dimpled discs. The ion irradiations were performed at the JANNuS (Joint Accelerators for Nano-science and Nuclear Simulation) multi-beam irradiation facility at CEA, Saclay, France, using a 3 MV Pelletron accelerator, and a 2.5 MV single ended Van de Graaf, coupled to an irradiation chamber, for performing simultaneous single or dual beam ion irradiations. $2 \mathrm{MeV} \mathrm{Fe}^{2+}$ self-ions were used to reach a fluence equal to $1.38 \times 10^{21}$ ions. $\mathrm{m}^{-2}$. The resulting depth profile of the displacement damage, measured in displacements per atom (dpa), is given in Fig. 1. It was estimated using SRIM in a Fe matrix, using a displacement threshold of $40 \mathrm{eV}$, and based on the Kinchin-Pease calculation, as recommended by Stoller et al. [26]. The maximum dose at the damage peak, located at 550 $600 \mathrm{~nm}$ from the irradiated surface, was $157 \mathrm{dpa}$. The damage rate at the peak was $\sim 3.3 \times 10^{-3}$ dpa/s. For the dual beam case, $2 \mathrm{MeV} \mathrm{He}^{+}$ions were co-implanted along with the Fe beam, to reach a fluence of $8.4 \times 10^{20}$ ions.m ${ }^{-2}$. To implant He at the damaged zone created by the Fe ions, an energy degrader consisting of a combination of thin aluminium foils was used on the He beam, as described in Appendix A of Ref. [11]. The helium implantation profile is not homogeneous because of a significant ion loss due to divergence, after scattering in the foils. 
The implantation profile was calculated after this correction and is given in Fig.1. The helium to dpa ratio at the damage peak was 17 appm He/dpa. The profile of the injected Fe self-ions is also given in Fig.1. After irradiations, transverse focused ion beam (FIB) specimens were extracted from the irradiated discs, to access the complete depth distribution of the irradiation damage. These specimens were prepared by lift-out technique using a FEI Helios 650 dual beam FIB machine at CEA-Saclay, France. The initial lift-out was done using $30 \mathrm{keV}$ Ga ions. While thinning, the energy of the ions was decreased progressively up to $2 \mathrm{keV}$ to minimise Ga induced defects. The irradiated microstructure was characterized by conventional TEM, utilizing a LaB6 based $200 \mathrm{keV}$ Jeol JEM 2100 TEM, equipped with a Gatan Orius high resolution CCD camera and a Gatan GIF Quantum spectrometer for EELS (electron energy loss spectroscopy). Through-focal series imaging technique [27] was used to image the cavities in the microstructure, which appear bright with a dark Fresnel fringe around when the objective lens of the TEM is under-focused and vice-versa. For the sake of simplicity, only under-focused images are presented in this article. Depth variation of void swelling was estimated by calculating the volume fraction of the cavities observed in the TEM micrographs. Where ever possible, care was taken to consider the cavity shapes while calculating their volume. The error bars were also calculated on the value of void swelling. The main sources of error were in (i). thickness determination, (ii). statistical error in the number of cavities in the analysed zone and (iii). the error in determining cavity size. Specimen thickness was determined by measuring the plasmon peak intensity in EELS and utilizing the log-ratio model [28]. The error in thickness, obtained by performing repeated measurements on the same zone, was about $\pm 15 \%$. The statistical error on the cavity count was minimised by analysing a larger zone to have sufficient number of cavities to consider. The error in cavity size was estimated by making repeated size measurements on the microstructure on the under-focused TEM images. It was strongly dependent on the cavity 
size. For cavities between 5 - $20 \mathrm{~nm}$ size, it was 11\%. Larger cavities, beyond $20 \mathrm{~nm}$ size, had error in the range of 3 - 5\%. All these errors were included for calculation of each swelling data. For faceted cavities, the longest distance was considered as the size, while for spherical cavities, the size is represented by their diameter. Cavity number density was also estimated for the specimens. The error bar on this value was estimated using the error in the thickness measurement and the statistical error in the number of cavities considered for the analysis.

Fig. 2 shows the bright field TEM images of cavities formed after the high dose irradiations, with and without helium co-implantation. TEM images in Figs. 2a and 2b were taken on (001) zone axis, which show that most of the cavities were faceted. Figs. 2c and 2d show the entire depth distribution of cavities in the samples. For a better understanding, quantitative values of the depth variation of cavity size, number density and void swelling, extracted from the TEM images, is shown in Fig. 3. The TEM images and the quantitative results denote a denuded zone up to 100 nm below the irradiated surface for both the irradiation conditions. Beyond that, addition of helium was seen to reduce the size of cavities and to increase their number density drastically. This behavior induced a very strong reduction of void swelling upon helium co-implantation all along the damage depth (Fig. 3c). As for example, in the zone between 300 - $400 \mathrm{~nm}$, void swelling was estimated to be $8.5 \%$ for the sample with no helium, which reduced to only $\sim 1 \%$ when helium was co-implanted. In this case, the average cavity size was $67 \mathrm{~nm}$ for the former and only $6.8 \mathrm{~nm}$ for the later, with almost two orders of magnitude higher number density. Maximum difference of swelling in the two cases was noted for the regions between 200 - $300 \mathrm{~nm}$. The trend of higher average cavity size when no helium was present was true for the entire damage depth, while the sample with helium always had higher number density along the depth. Since void swelling was always higher for the sample with no helium, it is evident that swelling was dominated by the cavity size and not by the number density. 
From these results, it is very clear that void swelling will not be always higher when helium is injected simultaneously. The results agree with the works of Brimbal et. al [11] and Kuramoto et al [15] mentioned previously who also reported swelling drop upon helium injection in bcc Fe. Thus, caution must be addressed when interpreting or analysing the existing literature results or future experimental results on swelling behaviour of steels in terms of helium. In the present study, smaller sized cavities (2 - $4 \mathrm{~nm}$ in size) were present all along the target depth for the sample with helium co-implantation, which suggests that the nucleation of cavities was still on-going. In contrast, no such small cavities were present when helium was not implanted simultaneously, indicating that the nucleation phase of the cavities was over and the microstructure was controlled by cavity growth. This agrees with the stabilization of vacancy clusters by helium as proposed by Fu et al [12], which would directly induce higher cavity number density in experimental situations such as ours. Other relevant works available in the literature are not on pure bcc Fe, but usually on fcc austenitic steels. For example, in a relatively old study by Packan and Farrell [23] on the influence of the method of gas implantation on void swelling of 316 stainless steel, similar results were seen when helium was co-implanted. At $900 \mathrm{~K}$ up to 70 dpa, swelling reached 18\% when no helium was present, and dropped to $11 \%$ when helium was simultaneously injected to 20 appm He/dpa. More details of the microstructure are published by the authors in Ref. [29] where once again it was seen that helium reduced cavity sizes (90 nm without helium and $49 \mathrm{~nm}$ with helium) and increased number density ( $4.2 \times 10^{20} \mathrm{~m}^{-3}$ without helium and $1.3 \times 10^{21} \mathrm{~m}^{-3}$ with helium). Thus, the drop in net swelling was due to the reduction of the cavity sizes. In a related study, the authors observed this swelling reduction over a wide range of temperature (840 - $1100 \mathrm{~K})$ [30].

Within the framework of the dislocation bias model [31, 32], it is known that swelling is induced by the effect of bias i.e. preferential migration of interstitials at dislocations which 
leaves vacancy super-saturation in the matrix. The cavity begins to grow more rapidly in response to an excess flux of vacancies over interstitials. However, this excess flux of vacancies, and hence cavity growth, is strongly dependent on the relative point-defect (PD) sink strengths of the microstructural features including the cavities themselves. But cavities are unbiased or neutral sinks because they do not have any associated strain fields, which means no preferential absorption for any kind of defect. If the number density of cavities increases sufficiently in the irradiated material due to helium, it is possible that they can become the dominant sinks for the mobile PDs or their clusters instead of the dislocation lines or the dislocation loops. In that case, the relative interstitial flux towards the dislocations would be reduced, reducing the vacancy flux towards the cavities due to enhanced recombination. Cavities would then be unable to grow, thereby, restricting swelling. The quantitative term to explain this behaviour is the ratio of the sink strengths of the dislocations and cavities [32] given by

$$
Q=\frac{Z_{i, v}^{d} L}{Z_{i, v}^{c} 4 \pi r_{c} N_{c}}
$$

In this equation, $Z_{i, v}^{d}$ and $Z_{i, v}^{c}$ are the bias factors of the dislocations and cavities (for interstitials and vacancies) respectively, $\mathrm{L}$ is the total dislocation length, $r_{c} N_{c}$ is the product of the average cavity size and cavity number density. For neutral sinks like cavities, bias factor $Z_{i, v}^{c}$ is taken as unity because cavities are unbiased. Based on this Q-value, an experimental data set on steady state swelling in austenitic stainless steels and F-M steels is collected by Mansur and Lee [32]. It shows that the swelling rate shows a peak when $Q=1$, i.e. when the bias by dislocations and cavities is equal. If $\mathrm{Q}>1$, the dislocation density is high enough to significantly reduce the vacancy super-saturation needed to cause swelling. This leads to swelling decrease. When $\mathrm{Q}<1$, the bias is controlled by the cavities which are in high 
number density. In that case, swelling drops again because cavity growth is hindered. In our case, since helium is not expected to drastically affect the dislocation loop microstructure because of a very weak binding between helium and self-interstitial atoms [33], it is reasonable to consider that the samples with and without helium co-implantation will have similar loop microstructure. Due to this, the dislocation bias for both these irradiation conditions should also be similar. Then, Q and hence swelling would be inversely proportional to the cavity sink strength, shown as $Q \propto\left(Z_{i, v}^{c} 4 \pi r_{c} N_{c}\right)^{-1}$. Taking $Z_{i, v}^{c}$ equal to unity, the calculated depth variation of the cavity sink strength for the irradiation without and with simultaneous helium co-implantation in bcc Fe in our case is shown in Fig. 4. In the entire damage depth, the sink strength of the cavities was higher due to a higher cavity number density when helium was co-implanted. This, hence, explains why void swelling was less when helium was co-implanted. In austenitic stainless steels, dual beam ion irradiations at $873 \mathrm{~K}$ by Katoh et al. [34] and neutron irradiations at 773 - $793 \mathrm{~K}$ by Stoller [35] show that swelling peaks at intermediate He/dpa ratios. Void swelling was seen to increase for He/dpa levels between 0 to $\sim 15$. For higher He/dpa levels, void swelling decreased. This behaviour was explained using similar arguments based on the variation of the sink strength ratio Q mentioned earlier. The initial increase in swelling was due to the early onset of cavity nucleation induced by helium, which continued to increase until the dislocation and cavity bias are equal. Beyond that, the excessive nucleation changed the bias towards cavities due to which the swelling decreased. In our case, He/dpa varied from $~ 5$ appm He/dpa in near surface areas to 17 appm He/dpa at the damage peak. But all along the depth, swelling was less when helium was present. We did not see a similar peak in swelling appearing at a given He/dpa. We attribute this to the irradiation conditions in terms of dpa, dpa rate and primary knock-on spectrum which vary strongly along the damage depth. Thus, a direct comparison with the He/dpa effect, as seen for austenitic steels, cannot be made. Nevertheless, the Q- 
values along the damage depth in our case were always higher for the sample with coimplanted helium, which implies that we were always in the condition where the bias was dominated by the cavities.

TEM results in Figs. 2 and 3 also revealed that cavity size and the associated void swelling reduced significantly along the damage depth in the areas near the damage peak. Since the dose increases along the specimen depth, and is maximum at the damage peak, such a swelling trend is unexpected. Since the dose rate in our study varied from $1.4 \times 10^{-3} \mathrm{dpa} / \mathrm{s}$ at the surface to only $\sim 3.3 \times 10^{-3} \mathrm{dpa} / \mathrm{s}$ at the damage peak, the observed decrease in cavity size and reduced void swelling is not a dose rate effect. During ion irradiations, the ions deposited in the material lie very close to the damage peak. In the present study, as visible in Fig. 1, the implantation peak of the self-ions was at $\sim 700 \mathrm{~nm}$, with a long tail towards the damage peak around $550-600 \mathrm{~nm}$. At the implantation peak, the amount of injected Fe ions was $\sim 40000$ appm (4 at.\%), which reduced to 20000 - 30000 appm at the damage peak. Based on this, we believe that the unexpected swelling suppression at the damage peak is due to the injected ions which recombine with the radiation induced vacancy clusters, giving rise to the wellknown injected interstitial effect. As a result, cavities reduce in the areas around the damage peak, thereby artificially reducing void swelling. Many previous ion irradiation studies performed on a variety of metallic materials have reported similar observations [36-43]. Rate theory simulations have also shown that injected ions can strongly reduce void nucleation rate [39] and suppress void growth [41]. More recently, injected interstitials were also shown to influence the formation of radiation induced $\alpha^{\prime}$ phase formation in ion irradiated Fe-Cr alloys [44]. This is purely an artefact of ion irradiation experiments. Thus, to obtain reliable experimental results after ion irradiations, it is imperative to avoid the damage peak area for characterizing of radiation induced defects. 
In summary, high dose self-ion irradiations with and without helium co-implantation on high purity bcc Fe at $773 \mathrm{~K}$ revealed a strong void swelling reduction due to helium coimplantation. TEM analysis on FIB foils revealed that swelling reduction was primarily due to strong reduction in cavity sizes, but with an order of magnitude higher cavity number density. The results, explained using the sink strength ratios of cavities and dislocations, highlight that void swelling will not be always higher when helium is co-implanted. Helium addition will enhance cavity nucleation. However, the cavity number density can become high to an extent that they become the major sinks for PDs. In such scenarios, since cavities are neutral sinks, their growth is limited, thereby restricting void swelling. The analysis of the depth distribution of cavities also revealed that injected interstitials artificially reduce void swelling adjacent to the damage peak in ion irradiation studies.

\section{Acknowledgements}

This work was supported by the joint program “CPR ODISSEE” funded by AREVA, CEA, CNRS, EDF and Mécachrome under contract No. 070551. The authors are thankful to Dr. Thomas Jourdan for fruitful discussions.

\section{References}

[1] R. Klueh, D. Harries, High-Chromium Ferritic and Martensitic Steels for Nuclear Applications, ASTM, Bridgeport, 2001.

[2] J.-L. Boutard , A. Alamo A, R. Lindau , M. Rieth, Fissile core and Tritium-Breeding

Blanket: structural materials and their requirements C. R. Phy. 9 (3-4) (2008)287 - 302.

[3] N. Baluc, R. Schäublin, P. Spätig, M. Victoria, On the potentiality of using ferritic/martensitic steels as structural materials for fusion reactors, Nucl. Fusion 44 (2004) $56-61$ 
[4] Y. Dai, G. R. Odette, T. Yamamoto, The Effects of Helium in Irradiated Structural Alloys, in: R.J.M. Konings, T. R. Allen, R. E. Stoller, S. Yamanaka (Eds.), Comprehensive Nuclear Materials Vol.1. Elsevier, 2012, pp. 141-193.

[5] M.R. Gilbert, S.L. Dudarev, S. Zheng, L.W. Packer and J.-Ch. Sublet, An integrated model for materials in a fusion power plant: transmutation, gas production, and helium embrittlement under neutron irradiation, Nucl. Fusion 52 (8) (2012) 083019 (12pp).

[6]. T. Schuler, C. Barouh, M. Nastar, and C-C. Fu, Equilibrium Vacancy Concentration Driven by Undetectable Impurities, Phys. Rev. Lett. 115 (2015) 015501.

[7]. C. Barouh, T. Schuler, C-C Fu and Maylise Nastar, Interaction between vacancies and interstitial solutes ( $\mathrm{C}, \mathrm{N}$, and $\mathrm{O}$ ) in $\alpha-\mathrm{Fe}$ : From electronic structure to thermodynamics, Phys. Rev. B 90 (2014) 054112.

[8]. C. Barouh, T. Schuler, C-C Fu and T. Jourdan, Predicting vacancy-mediated diffusion of interstitial solutes in $\alpha$-Fe, Phys. Rev. B 92 (2015) 104102.

[9] R. Schäublin, J. Henry, Y. Dai, Helium and point defect accumulation: (i) microstructure and mechanical behaviour, CR. Phys. 9(3-4) (2008) 389-400.

[10] H. Trinkaus, B.N. Singh, Helium accumulation in metals during irradiation - where do we stand?, J. Nucl. Mater. 323 (2-3) (2003) 229-242.

[11] D. Brimbal, E. Meslin, J. Henry, B. Décamps, A. Barbu, He and Cr effects on radiation damage formation in ion-irradiated pure iron and Fe-5.40 wt.\% Cr: A transmission electron microscopy study, Acta Mater. 61 (13) (2013) 4757-4764.

[12] C. C. Fu, F. Willaime, Ab initio study of helium in $\alpha-$ Fe: Dissolution, migration, and clustering with vacancies, Phys. Rev. B. 72 (2005) 064117. 
[13] M. J. Caturla, C. J. Ortiz, C. C. Fu, Helium and point defect accumulation: (ii) kinetic modeling, C. R. Phys. 9 (3-4) (2008) 401-408.

[14] T. Ishizaki , Q. Xu, T. Yoshiie, S. Nagata, T. Troev, Helium and point defect accumulation: (ii) kinetic modelling, J. Nucl. Mater. 307-311 (2002) 961-965.

[15] E. Kuramoto , N. Yoshida, N. Tsukuda, K. Kitajima, N. H. Packan, M. B. Lewis , L. K. Mansur, Simulation irradiation studies on iron, J. Nucl. Mater. 104 (198) 1091-1095.

[16]. E. Getto, E, Z. Jiao, A. M. Monterrosa, K. Sun, G. S. Was, Effect of preimplanted helium on void swelling evolution in self-ion irradiated HT9, J. Nucl. Mater. 462 (2015) $458-469$.

[17]. Q, Xu, T. Yoshiie, K. Sato, Effects of hydrogen and helium produced by transmutation reactions on void formation in copper isotopic alloys irradiated with neutrons, J. Nucl. Mater. 386 - 388 (2008) 363-366.

[18]. T. Tanaka, K. Oka, S. Ohnuki, S. Yamashita, T. Suda, S. Watanabe, E. Wakai, Synergistic effect of helium and hydrogen for defect evolution under multi-ion irradiation of Fe-Cr ferritic alloys, J. Nucl. Mater. 329 (2004) 294-298.

[19]. E. A. Kenik, The Influence of helium on microstructural evolution of stainless steel, J. Nucl. Mater., 85 \& 86 (1979) 659-663.

[20]. Y.E. Kupriiyanova, V.V. Bryk, O.V. Borodin, A.S. Kalchenko, V.N. Voyevodin , G.D. Tolstolutskaya , F.A. Garner, Use of double and triple-ion irradiation to study the influence of high levels of helium and hydrogen on void swelling of $8 \mathrm{e} 12 \% \mathrm{Cr}$ ferritic-martensitic steels, J. Nucl. Mater. 468 (2016) 264-273. 
[21]. S.K. McLaurin, G.L. Kulcinski, Effects of temperature and helium on void formation in self-ion irradiated aluminum, J. Nucl. Mater. 117 (1983) 208-212.

[22]. K. Yutani, H. Kishimoto, R. Kasada, A. Kimura, Evaluation of helium effects on swelling behavior of oxide dispersion strengthened ferritic steels under ion irradiation, J. Nucl. Mater., 367-370 (2007) 423-427.

[23]. N. H. Packan, K. Farrell, Simulation of first wall damage: Effects of the method of gas implantation, J. Nucl. Mater. 85-86 Part 2 (1979) 677-681.

[24]. J. Delaplace, N. Azam and L. LeNaour, Gonflement du nickel irradie par des ions $\mathrm{Ni}^{+}$de moyenne energie, J. Nucl, Mater. 47 (1973) 278.

[25]. T. Kimoto, E.H. Lee, L.K. Mansur, Effects of helium injection mode on void formation in Fe-Ni-Cr alloys, J. Nucl. Mater. 158 (1988) 166-178.

[26]. R.E. Stoller, M.B. Toloczko, G.S. Was, A.G. Certain, S. Dwaraknath, F.A. Garner, On the use of SRIM for computing radiation damage exposure, Nucl. Instrum. Methods Phys. Res. Sect. B Beam Interact. Mater. Atoms 310 (2013) 75-80.

[27] M. L. Jenkins, M. A. Kirk, Characterization of radiation damage by transmission electron microscopy. IOP Publishing Ltd., 2001.

[28] R. Egerton, Electron energy-loss spectroscopy in the electron microscope, $3^{\text {rd }}$ ed. New York, Springer, 2011.

[29] K. Farrell, M. B. Lewis, N. H. Packan, Simultaneous bombardment with helium, hydrogen, and heavy ions to simulate microstructural damage from fission or fusion neutrons, Scripta. Metall. Mater., 12 (12) (1978) 1121-1124. 
[30] K. Farrell, N. H. Packan, A helium-induced shift in the temperature dependence of swelling, J. Nucl. Mater. 85-86 Part 2 (1979) 683-687.

[31] G.S. Was, Fundamentals of Radiation Materials Science, Berlin: SpringerVerlag, 2007.

[32] L. K. Mansur, E. H. Lee, Theoretical basis for unified analysis of experimental data and design of swelling-resistant alloys, J. Nucl. Mater. 179-181 Part 1 (1991) 105-110.

[33] L. Ventelon, B. D. Wirth, C. Domain C. J. Nucl. Mater. 351 (2006), 119.

[34] Y. Katoh, Y. Kohno, A. Kohyama, Dual-ion irradiation effects on microstructure of austenitic alloys, J. Nucl. Mater. 205 (1993) 354-360.

[35] R. E. Stoller, The influence of helium on microstructural evolution: Implications for DT fusion reactors, J. Nucl. Mater. 174 (2-3) (1990) 289-310.

[36] H. Tanigawa, M. Ando, Y. Katoh, T. Hirose, H. Sakasegawa, S. Jitsukawa, A. Kohyama, T. Iwai, Response of reduced activation ferritic steels to high-fluence ion-irradiation, J. Nucl. Mater. 279 (3) (2001) 279-284.

[37] F. A. Garner, Impact of the injected interstitial effect on ion-induced void swelling in austenitic and ferritic-ODS alloys, Workshop on Ion Beam Simulation of High Dose Neutron Irradiation, University of Michigan USA, 2014.

[38] E. H. Lee, L.K. Mansur, M. H. Yoo, Spatial variation in void volume during charged particle bombardment — the effects of injected interstitials, J. Nucl. Mater. 85-86 Part 1 (1979) 577-581.

[39] D. L. Plumton, W. G. Wolfer, Suppression of void nucleation by injected interstitials during heavy ion bombardment, J. Nucl. Mater. 120 (2-3) (1984)245-253. 
[40] F. A. Garner, Impact of the injected interstitial on the correlation of charged particle and neutron-induced radiation damage, J. Nucl. Mater. 117 (1983) 177-197.

[41] A. D. Brailsford, L. K. Mansur, Effect of self-ion injection in simulation studies of void swelling, J. Nucl. Mater. 71 (1) (1977) 110-116.

[42] J. B. Whitley, G. L. Kulcinski, P. Wilkes, H. V. Smith Jr., The depth dependent damage profile in nickel irradiated with nickel or copper ions, J. Nucl. Mater. 79 (1) (1979) 159-169.

[43] L. Shao, C.-C. Wei, J. Gigax, A. Aitkaliyeva, D. Chen, B. H. Sencer, F. A. Garner, Effect of defect imbalance on void swelling distributions produced in pure iron irradiated with 3.5 MeV self-ions, J. Nucl. Mater. 453 (1-3) (2014) 176-181.

[44]. O. Tissot, C. Pareige, E. Meslin, B. Décamps, J. Henry, Influence of injected interstitials on $\alpha^{\prime}$ precipitation in Fe-Cr alloys under self-ion irradiation, Materials Research Letters 5 (2), (2017) 117-123. 
Table 1: Nominal impurity concentration of the high purity bcc Fe.

\begin{tabular}{|l|c|l|l|l|l|l|}
\hline \multirow{2}{*}{ Material } & $\mathrm{Cr}$ & \multicolumn{1}{c|}{$\mathrm{C}$} & \multicolumn{1}{c|}{$\mathrm{Si}$} & $\mathrm{O}$ & $\mathrm{N}$ & $\mathrm{P}$ \\
& wt.\% & wt. ppm & wt. ppm & wt. ppm & wt. ppm & wt. ppm \\
\hline Pure Fe & $<2 \mathrm{ppm}$ & 4 & 2 & 4 & 1 & $<5$ \\
\hline
\end{tabular}

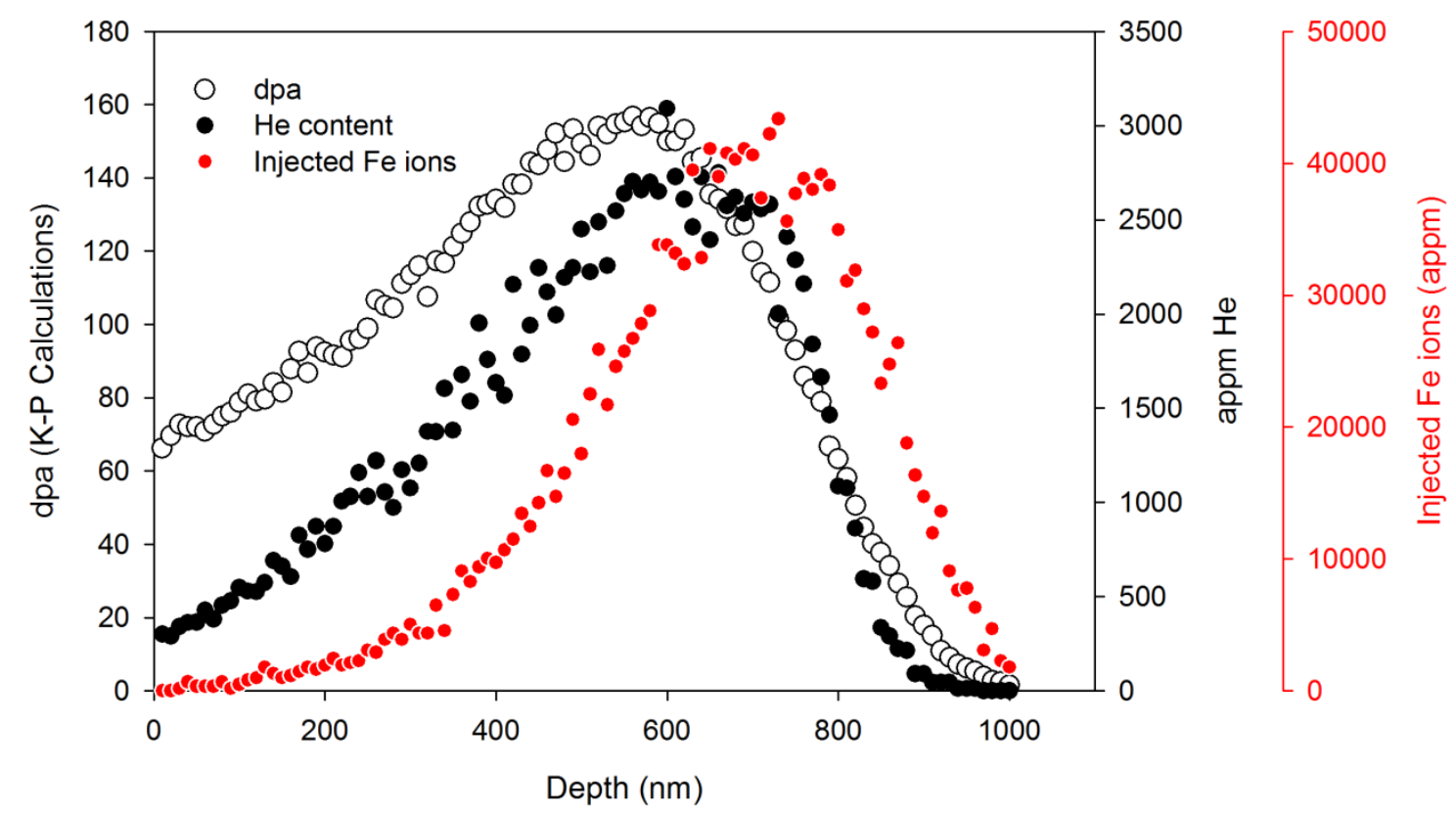

Figure 1: Depth profile of displacement damage, helium implantation profile (in appm) and injected self-ion profile (in appm) obtained for Fe matrix by SRIM calculations. 

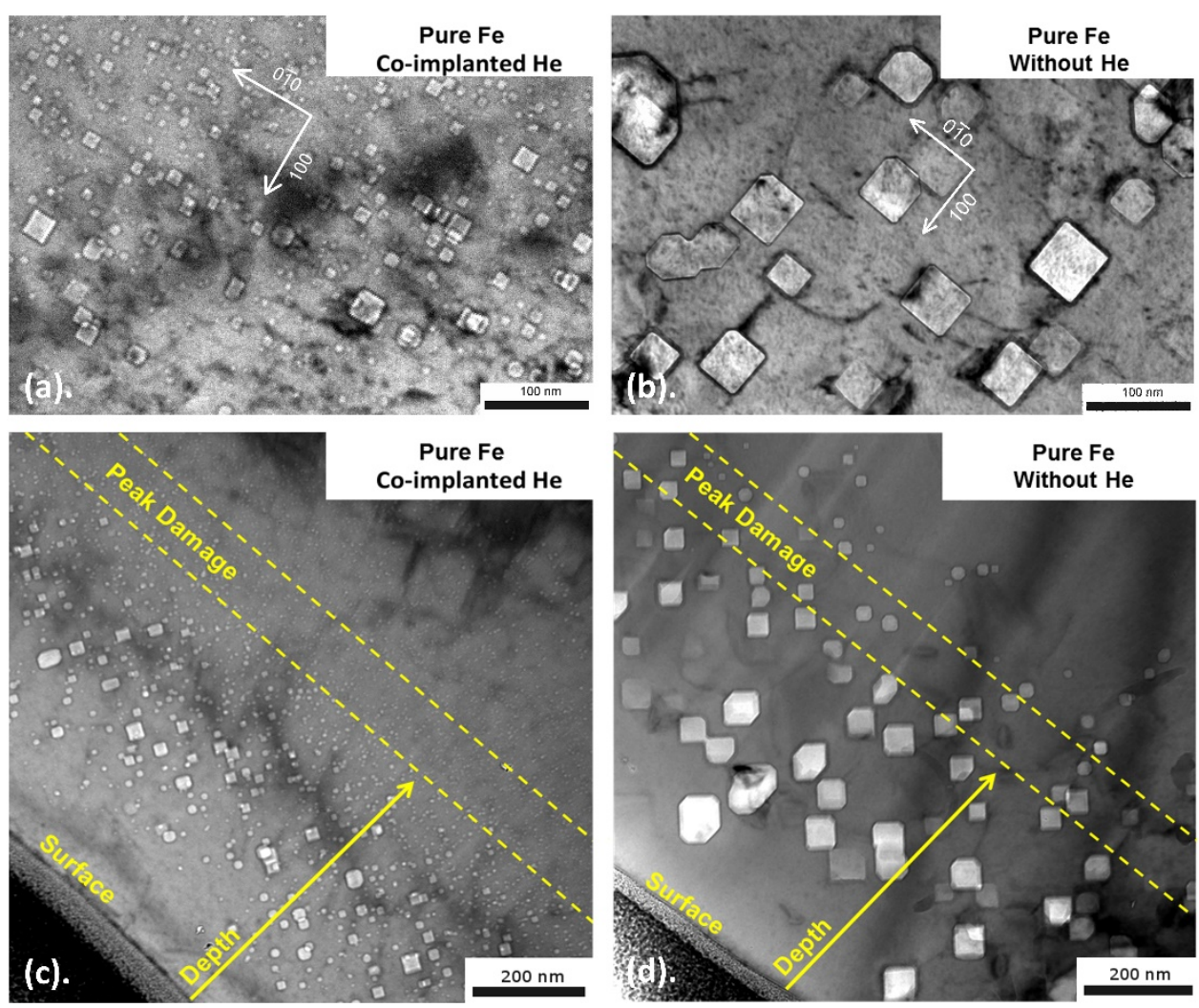
Figure 2: BF TEM image of cavities in bcc Fe after irradiation at $773 \mathrm{~K}$ to 157 dpa. (a). helium co-implanted to 17 appm He/dpa at the damage peak and (b) without helium coimplantation. Imaging performed on (001) zone axis. (c), (d). TEM images of the depth distribution of cavities in bcc Fe with and without helium co-implantation respectively (under-focus $=-1136 \mathrm{~nm}$ ).
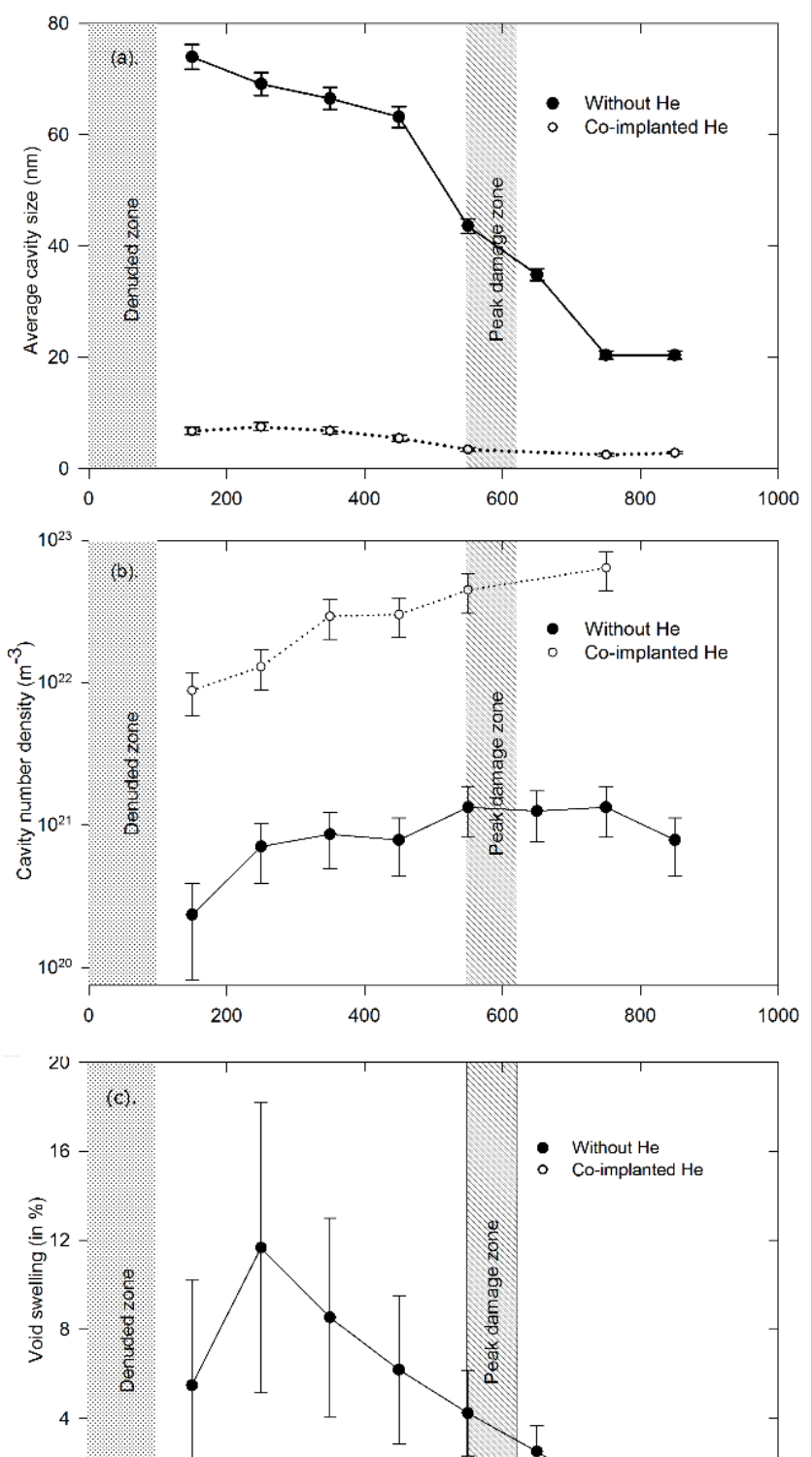
Figure 3: Comparison of depth distribution of average cavity size, number density and void swelling in bcc Fe irradiated at $773 \mathrm{~K}$ without and with co-implantation of helium.

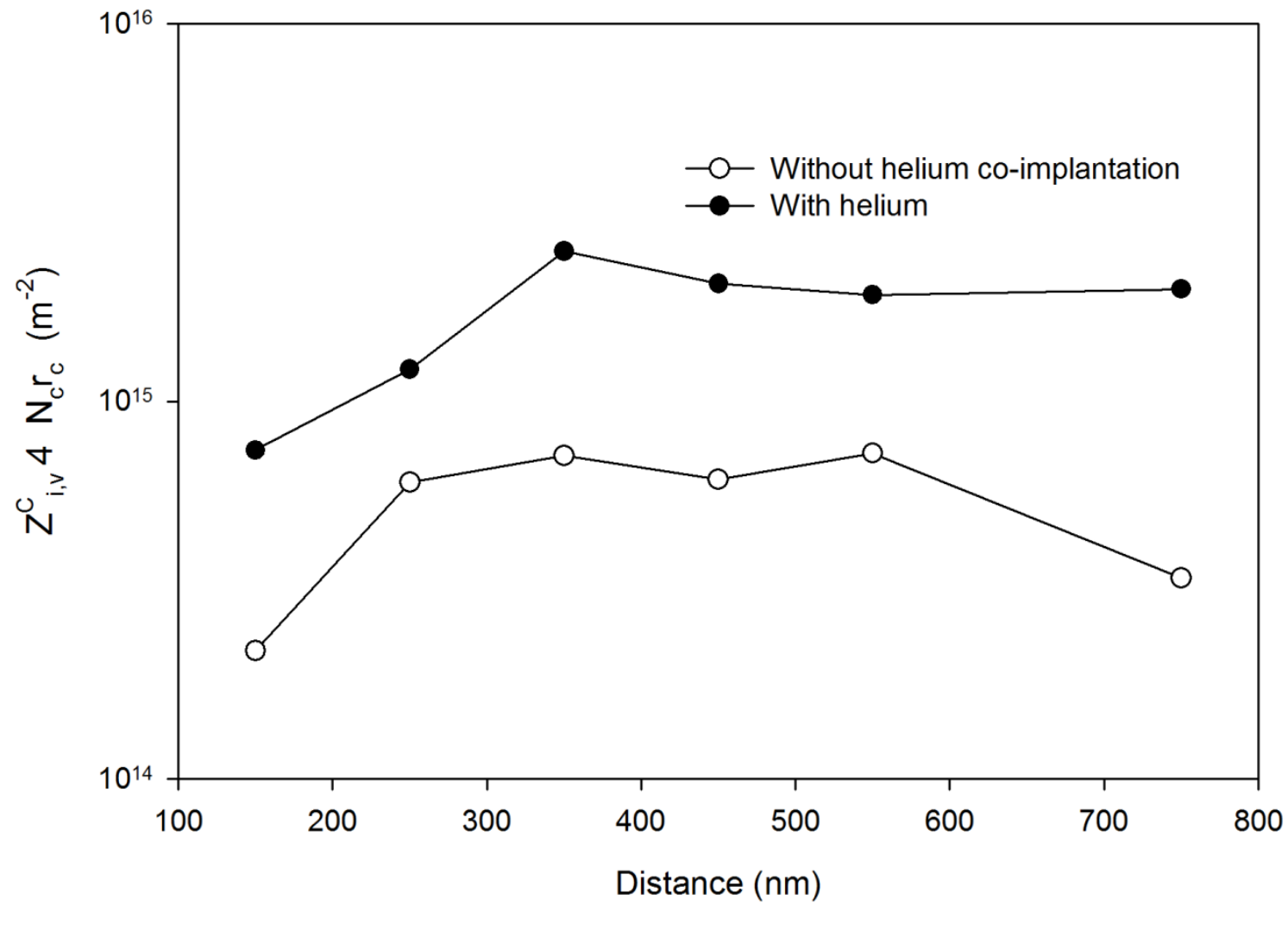


Figure 4: Depth variation of the cavity sink strength estimated in the irradiated bcc Fe. 